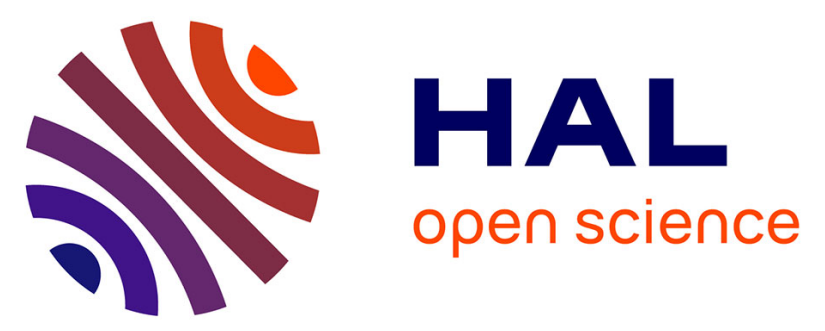

\title{
Direct graphene growth on transitional metal with solid carbon source and its converting into graphene/transitional metal oxide heterostructure
}

Jeongho B Park, Tyson C Back, Steven B Fairchild, William C Mitchel, Said Elhamri, John B Boeckl, Dominique C Martinotti, Ludovic C Douillard, Patrick C Soukiassian

\section{To cite this version:}

Jeongho B Park, Tyson C Back, Steven B Fairchild, William C Mitchel, Said Elhamri, et al.. Direct graphene growth on transitional metal with solid carbon source and its converting into graphene/transitional metal oxide heterostructure. Carbon, 2017, 116, pp.303-309. 10.1016/j.carbon.2017.01.072 . cea-01520061

\section{HAL Id: cea-01520061 https://hal-cea.archives-ouvertes.fr/cea-01520061}

Submitted on 9 May 2017

HAL is a multi-disciplinary open access archive for the deposit and dissemination of scientific research documents, whether they are published or not. The documents may come from teaching and research institutions in France or abroad, or from public or private research centers.
L'archive ouverte pluridisciplinaire HAL, est destinée au dépôt et à la diffusion de documents scientifiques de niveau recherche, publiés ou non, émanant des établissements d'enseignement et de recherche français ou étrangers, des laboratoires publics ou privés. 


\title{
Direct graphene growth on transitional metal with solid carbon source and its converting into graphene/transitional metal oxide heterostructure
}

\author{
Jeongho Park ${ }^{\text {a, * }}$, Tyson Back ${ }^{\text {a, b, c }}$, Steven B. Fairchild ${ }^{a}$, William C. Mitchel ${ }^{\text {a }}$, \\ Said Elhamri ${ }^{\mathrm{d}}$, John Boeckl ${ }^{\mathrm{a}}$, Dominique Martinotti ${ }^{\mathrm{e}}$, Ludovic Douillard ${ }^{\mathrm{e}}$, \\ Patrick Soukiassian ${ }^{\text {e, } \mathrm{f}}$ \\ a Air Force Research Laboratory, Materials and Manufacturing Directorate (AFRL/RXA) Wright-Patterson AFB, OH, 45433-7707, USA \\ ${ }^{\mathrm{b}}$ University of Dayton Research Institute, Dayton, OH, 45469-0170, USA \\ c Center of Excellence for Thin Film Research and Surface Engineering, University of Dayton, Dayton, OH 45469-0170, USA \\ ${ }^{\mathrm{d}}$ Departments of Physics, University of Dayton, Dayton, $\mathrm{OH}, 45469$, USA \\ e Commissariat à l'Energie Atomique et aux Energies Alternatives, SPEC CEA, CNRS, Université Paris-Saclay, F-91191, Gif sur Yvette Cedex, France \\ ${ }^{\mathrm{f}}$ Université de Paris-Sud, F-91405, Orsay Cedex, France
}

\section{A R T I C L E I N F O}

\section{Article history:}

Received 19 September 2016

Received in revised form

19 January 2017

Accepted 23 January 2017

Available online 30 January 2017

\begin{abstract}
A B S T R A C T
The oxide/semiconductor structure is key to controlling current in electronic devices and $\mathrm{HfO}_{2}$ is a common gate material in conventional electronic devices due to its favorable dielectric properties. Graphene devices also require insulating gates. We demonstrate a unique direct growth approach to obtain the bottom gate structure (graphene $/ \mathrm{HfO}_{2} / \mathrm{n}-\mathrm{SiC}$ ). The present approach involves transfer of graphene grown by chemical vapor deposition (CVD) on $\mathrm{Cu}$ to oxidized Si wafers, a complex process prone to low yield and reduced performance. Furthermore, $\mathrm{HfO}_{2}$ is preferred to $\mathrm{SiO}_{2}$ because of its superior properties. The proposed concept consists of the direct deposition of graphene by solid carbon molecular beam epitaxy on $\mathrm{Hf}$ metal coated n-type $\mathrm{SiC}$, followed by oxygen intercalation to form $\mathrm{HfO}_{2}$. The oxygen intercalation will then convert the underlying $\mathrm{Hf}$ into $\mathrm{HfO}_{2}$ due to the strong affinity of $\mathrm{Hf}$ with oxygen. We identify the graphene $/ \mathrm{HfO}_{2}$ formation by Raman, X-ray photoelectron spectroscopy (XPS), Low energy electron diffraction (LEED), Low energy electron microscopy (LEEM) and electrical properties including Hall mobility and leakage current measurement.
\end{abstract}

๑) 2017 Elsevier Ltd. All rights reserved.

\section{Introduction}

In modern device technologies, the dielectric layers play an essential role to control charge transport in the in-plane channel region, which is the fundamental principle of logical and analog RF field-effect transistor (FET). In the proposed novel vertical tunneling field-effect transistor (TFET) architecture (dielectric/ Graphene(Gr)/dielectric/Gr/dielectric/substrate), the oxide dielectric materials also provide key functional structure for charge tunneling. $[1,2]$ The gate voltage through the substrate induces $E$ field across the dielectric layer and then allows manipulating the charge carrier type and concentration in graphene which cause the

\footnotetext{
* Corresponding author.

E-mail address: jeongho.park.1.ctr@us.af.mil (J. Park).
}

shift of Fermi level. This allows the vertical charge transport as well as in-plane transport [3]. In addition, dual gated graphene structure sandwiched between top and bottom dielectric layers allow the bandgap opening in graphene, allowing the extraordinary transport properties of graphene to be incorporated into next generation semiconductor devices [4]. However; due to the lack of satisfactory growth methods, all experimental implementations of the gated structure have been performed at the laboratory level by time consuming processes such as exfoliation and transfer. Recently, graphene formation on an oxide surface has been proposed by CVD method by using two step approach [5,6,7]. To overcome the low surface energy of oxide surfaces and improve graphene nucleation, low and high carbon gas flow have been adapted for graphene nucleation and growth. However, this approach is suffers from controllable graphene nucleation density and growth rate on the dielectric surface which results in small single crystal graphene 
domain [7]. The sublimation method of SiC surface allows the direct graphene growth on single crystal $\mathrm{SiC}$, but for use as FET is typically implemented as a top-gated structure. The dual gating structure is difficult to achieve. In order to overcome the drawback of the state of the art growth techniques and to provide scalable production route, we demonstrate a unique direct growth approach to obtain $\mathrm{Gr} /$ dielectric/n-SiC heterostructure platform.

The $\mathrm{HfO}_{2}$ thin dielectric layer will be used for the gating oxide materials. Hafnium-based oxides are an ideal candidate to replace silicon oxide as a gate insulator in a graphene FET device due to its high dielectric constant, good thermodynamic and mechanical stability. The dielectric constant of $\mathrm{HfO}_{2}$ is 25 , whereas the dielectric constant of $\mathrm{SiO}_{2}$ is only 3.9. The high dielectric constant has been shown to be better for charge impurities screening located in proximity to a graphene layer [8]. The thermal stability of $\mathrm{HfO}_{2}$, melting point $\left(2700^{\circ} \mathrm{C}\right)$, will be ideal for a high temperature graphene growth environment. A recent theoretical study showed that there is no chemical bonding at the graphene- $\mathrm{HfO}_{2}$ interface and its energetic stability is ruled by the van der Waals interaction [9]. In addition, $\mathrm{HfO}_{2}$ /graphene structures exhibited ultra high mobility compared to other oxide/graphene structures [10,11] and welldeveloped half-integer quantum Hall states and magnetoresistance oscillations [12], similar to that of pristine exfoliated graphene [8]. Due to the lack of direct graphene growth on $\mathrm{HfO}_{2}$, however, the graphene device structure is top gating, $\mathrm{HfO}_{2} / \mathrm{Gra}$ phene, that limits its application. For dual oxide structure such as $\mathrm{HfO}_{2} / \mathrm{Graphene} / \mathrm{SiO}$, the underneath $\mathrm{SiO}_{2}$ significantly reduce electronic properties of graphene due to strong interaction. To preserve pristine graphene properties in the graphene/oxide device structure, therefore, the direct formation of graphene $/ \mathrm{HfO}_{2}$ is desired. In this work, we first attempt to directly grow epitaxial graphene on $/ \mathrm{HfO}_{2}$ heterostructure by both solid carbon $\left(\mathrm{C}_{60}\right)$ molecular beam epitaxy (CMBE) and intercalation. The direct deposition of $\mathrm{C}_{60}$ results in graphene formation on $\mathrm{Hf}$ as well as $\mathrm{Hf}-\mathrm{C}$ due to carbon reduction. Since the metallic $\mathrm{HfC}$ cannot provide isolation between graphene and $\mathrm{n}-\mathrm{SiC}$, we adapt an $\mathrm{O}_{2}$ intercalation process, which allows converting $\mathrm{HfC}$ into $\mathrm{HfO}_{2}$ due to the strong affinity with oxygen.

\section{Experimental}

Since the direct epitaxial growth of graphene on $\mathrm{HfO}_{2}$ surface is the most straightforward route to obtain $\mathrm{Gr} /$ dielectric heterostructure, growth was first performed by deposition of $\mathrm{C}_{60}$ on the $\mathrm{HfO}_{2}$ surface directly. In addition, graphene growth was also performed on a metallic $\mathrm{Hf}$ surface. The $\mathrm{Hf}$ metal $(20 \mathrm{~nm})$ was deposited by pulsed laser deposition (PLD), followed by the oxidation of Hf metal layer. The deposition was performed in vacuum with a $10 \mathrm{~Hz}$ repetition rate and $\sim 5 \mathrm{~cm}$ target to substrate distance. The oxidation was performed for $45 \mathrm{~min}$ at $700{ }^{\circ} \mathrm{C}$ under $40 \mathrm{sccm} \mathrm{O}_{2}$ flow at atmosphere pressure to obtain a $\mathrm{HfO}_{2}$ layer on n$\mathrm{SiC}$. The graphene growth on both $\mathrm{HfO}_{2}$ and Hf surface was conducted by $\mathrm{C}_{60}\left(1.6 \times 10^{-7}\right.$ Torr $\mathrm{C}_{60}$ flux $)$ deposition at $1400{ }^{\circ} \mathrm{C}$ for $30 \mathrm{~min}$ in UHV by a carbon molecular beam epitaxy approach [13].

The samples were then characterized in-situ/ex-situ by X-ray photoelectron spectroscopy (XPS) and low energy electron diffraction (LEED) in a system previously described elsewhere.[14] Briefly, high resolution XPS scans were acquired with a pass energy of $20 \mathrm{eV}$ and $0.1 \mathrm{eV}$ step size. After acquisition the elemental regions were fitted with component peaks that consisted of a combination Gaussian and Lorentzian peak shapes. An additional asymmetry parameter was added to metallic components. Raman analysis was performed on a Renishaw spectrometer with a laser wavelength of $532 \mathrm{~nm}$. Low energy electron microscopy (LEEM) was performed on an Elmitec LEEM III instrument.

\section{Results and discussion}

Fig. 1 exhibits the $\mathrm{x}$-ray photoemission spectroscopy of graphene grown on $\mathrm{HfO}_{2}$. The spectra in Fig. 1 show the evolution of $\mathrm{C}$ $1 s$, Hf $4 f$, and $\mathrm{O} 1 \mathrm{~s}$ spectra at the each stage of process. The bottom panels of Fig. 1a-c exhibit photoemission results from the $\mathrm{SiC}$ substrate. The $\mathrm{C} 1 \mathrm{~s}$ peak from $\mathrm{SiC}$ is located at $283.4 \mathrm{eV}$. $01 \mathrm{~s}$ spectra indicate physisorbed oxygen contamination. As shown violet colored spectra of Fig. 1a-c, SiC C1s peak disappeared and a high binding energy (BE) peak resulting from carbon contamination is observed after oxidation of Hf metal. The Hf $4 f$ peak positions for each spin orbital coupling peak, Hf $4 f_{7 / 2}$ and $\mathrm{Hf} 4 f_{5 / 2}$, is located at 18.9 and $20.6 \mathrm{eV}$, respectively. The peak separation between splitting is $\sim 1.7 \mathrm{eV}$, which agrees with the reported values for $\mathrm{HfO}_{2}[15]$. The measured peak position for $\mathrm{Hf} 4 f$ shift to higher binding energy is due to charging effect. The corresponding 01s (Fig. 1c) peak for $\mathrm{HfO}_{2}$ was located at $532.3 \mathrm{eV}$, agreed well with reported values. The $\mathrm{Hf}$ and oxygen ratio is not stoichiometric but $\mathrm{Hf}$ rich with a ratio of $1-1.8$. After $\mathrm{C}_{60}$ deposition, $\mathrm{C} 1 \mathrm{~s}$ core level spectra clearly show the graphene formation, which is located at $284.1 \mathrm{eV}$ (top panel of Fig. 1a). An additional peak is observed at lower binding energy $(281.3 \mathrm{eV})$, which is the similar binding energy of $\mathrm{C} 1 \mathrm{~s}$ from HfC. Further support of $\mathrm{HfC}$ formation after $\mathrm{C}_{60}$ deposition was observed at $\mathrm{Hf} 4 f$ core level spectrum as shown in top pane of Fig. $1 \mathrm{~b}$. The Hf $4 f$ peak exhibits the shift to lower binding energy. The $\mathrm{Hf} 4 f_{7 / 2}$ and Hf $4 f_{5 / 2}$ are located at $14.1 \mathrm{eV}$ and $15.8 \mathrm{eV}$, respectively. Although the $\mathrm{Hf} 4 f$ binding energy between pure Hf metal and HfC is very close each other, the shift toward low binding energy allows determination between two chemical compositions. The BE as shown in Fig. 1b shows $0.2 \mathrm{eV}$ shift compared to the reported binding energy of pure $\mathrm{Hf} 4 f(14.3 \mathrm{eV})$.[16] O1s spectrum in Fig. 1c also shows disappearance of $\mathrm{HfO}_{\mathrm{x}}$ bonding peak after $\mathrm{C}_{60}$ deposition. These results suggest that the $C_{60}$ deposition converts the $\mathrm{HfO}_{2}$ into $\mathrm{HfC}$. The formation of $\mathrm{HfC}$ upon $\mathrm{C}_{60}$ deposition could be explained by a carbon-thermal reduction reaction [17]. A Gibbs free energy calculation [17] shows that $\mathrm{HfO}_{2}$ reacts with carbon to form $\mathrm{HfC}$ and release $\mathrm{CO}$ gas above $1300{ }^{\circ} \mathrm{C}$. The high substrate temperature, $1400^{\circ} \mathrm{C}$, during $\mathrm{C}_{60}$ deposition can initiate carbon thermal reduction reaction between $\mathrm{C}_{60}$ molecular and $\mathrm{HfO}_{2}$ surface. Since HfC exhibits metallic behavior, the obtained $\mathrm{Gr} / \mathrm{HfC}$ heterostructure is an unlikely candidate for electronic applications. To achieve the $\mathrm{G} /$ dielectric heterostructure, one should find the optimal conditions to either avoid $\mathrm{HfC}$ formation during $\mathrm{Cr}_{60}$ formation, or convert the formed $\mathrm{HfC}$ into $\mathrm{HfO}_{2}$ after graphene growth. One possible approach to resolve the issue is by the oxygen intercalation process. The intercalation method is currently widely studied because the intercalated graphene such as hydrogen, oxygen, and gold results in the quasi free-standing graphene by saturation of $\mathrm{sp}^{3}$ hybridization at the interface between graphene and substrate and shows significantly improved electric characteristic [18]. The intercalation process occurs due to strong affinity of Hf to oxygen, which allows $\mathrm{HfC}$ to be converted into $\mathrm{HfO}_{2}$.

Since HfC formation after $\mathrm{C}_{60}$ deposition is an inevitable byproduct of the growth process, direct graphene growth on $\mathrm{HfO}_{2}$ does not provide any advantage, Therefore, growth of the graphene on $\mathrm{Hf}$ metal instead of $\mathrm{HfO}_{2}$ was attempted, which was followed by oxygen intercalation to convert the $\mathrm{HfC}$ into $\mathrm{HfO}_{2}$. First, we investigate the as-grown graphene quality as a function of growth condition such as growth temperature and $C_{60}$ flux. Fig. 2 shows the Raman spectra of graphene grown at different growth temperatures. The graphene growth time and $\mathrm{C}_{60}$ flux were kept at $30 \mathrm{~min}$ and $1.6 \times 10^{-7}$ Torr. At the $850{ }^{\circ} \mathrm{C}$ growth temperature, Raman shows only the formation of amorphous carbon. By increasing growth temperature, we observe graphene growth on the Hf metal surface at above $950{ }^{\circ} \mathrm{C}$. The graphene fingerprint, 2D peak, is 

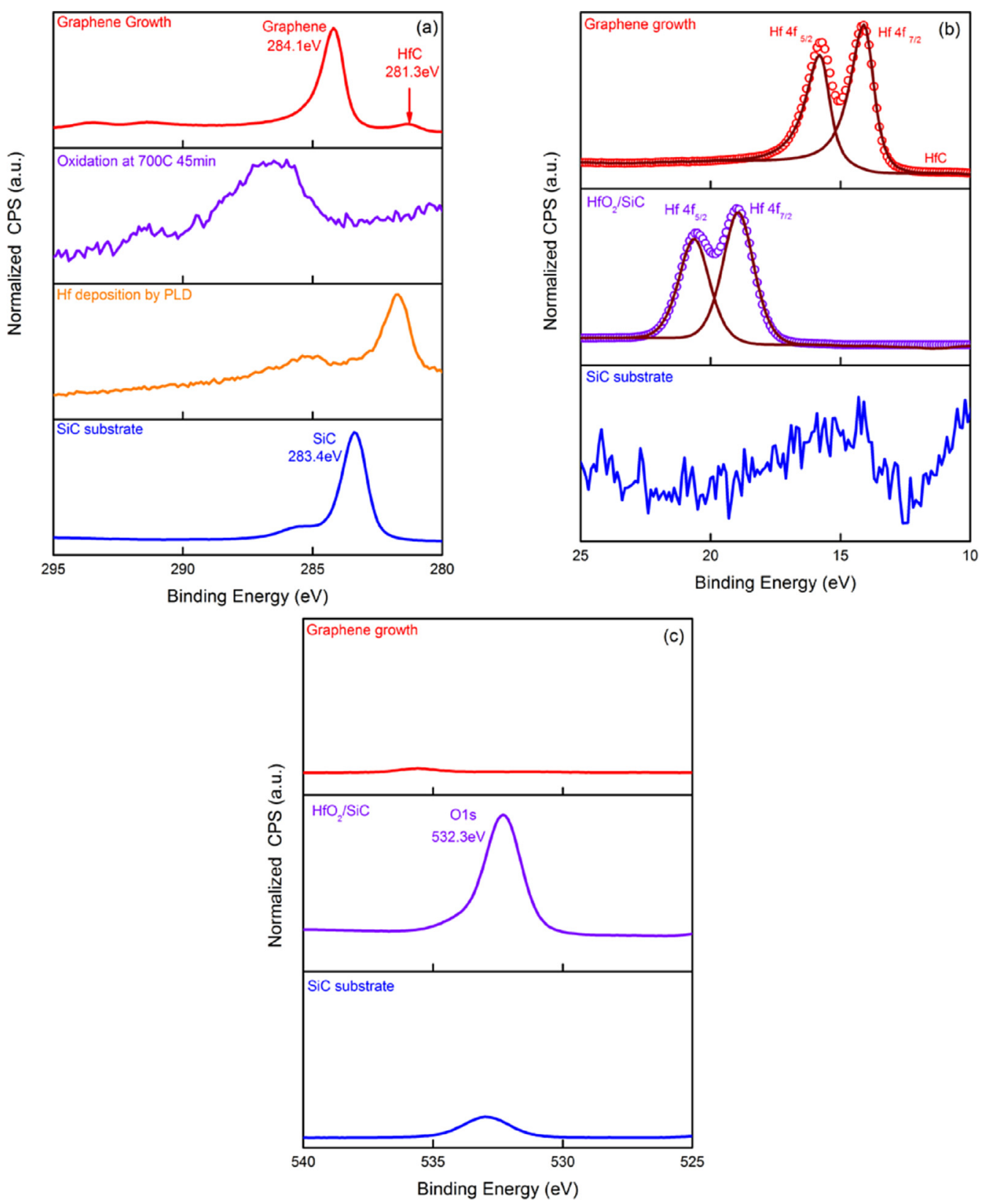

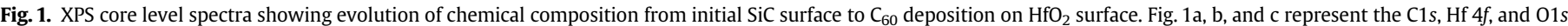

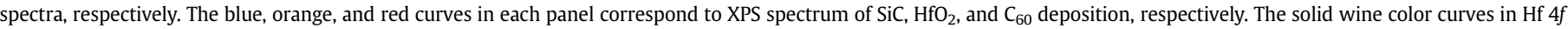
spectra (Fig. 1b) represent the curve fitting with Gaussian/Lorentizan combination. (A colour version of this figure can be viewed online.)

observed at $2678 \mathrm{~cm}^{-1}$. Since the D peak itself is not visible in the prinstine graphene and requires defects for its activation, one can qualitavely estimate the defects in graphene. The observation of the high $D / G$ ratio $(\sim 0.84)$ suggests the growth of the poor quality of graphene.[19] The D/G ratio continuously decreases as the growth temperature increases, which suggests the higher growth temperature yields improved graphene quality. The peak position of 2D and $G$ peak experiences the blue shift as temperature increases. The blue shift of $G$ and 2D peak resulted from either doping or strain in graphene. [20-24] However, we rule out the doping effect since it results in less sensitivity in 2D peak evolution, which is not observed in our data. Our data shows that blue shift of 2D peak is more dominant than that of $G$ peak. The blue shift of $2 \mathrm{D}$ peak results from compressive strain because the graphene and Hf metal have negative and positive thermal expansion coefficients, respectively.[25]. In addition, the absence of G peak splitting in our Raman spectra suggests that the graphene on Hf metal has biaxial strain [20]. The studies of $C_{60}$ flux dependence (from $0.8 \times 10^{-7}$ Torr to $3 \times 10^{-7}$ ) showed that the $2 \mathrm{D}$ peak experience the red shift as $\mathrm{C}_{60}$ flux increase, which indicates less compressive stained graphene formation at higher flux deposition (not shown in here).

To investigate the structural and morphological characteristics of the $\mathrm{Gr} / \mathrm{Hf}$ surface both LEED and LEEM analysis were employed. Fig. $2 \mathrm{~b}$ shows the LEED results from the $\mathrm{Gr} / \mathrm{Hf}$ sample. A hexagonal pattern is clearly evident which is consistent with graphene. The LEEM image shows differences in reflectivity we attribute to graphene formation on the surface. As further evidence of uniform growth the mirror electron microscopy to low energy electron 

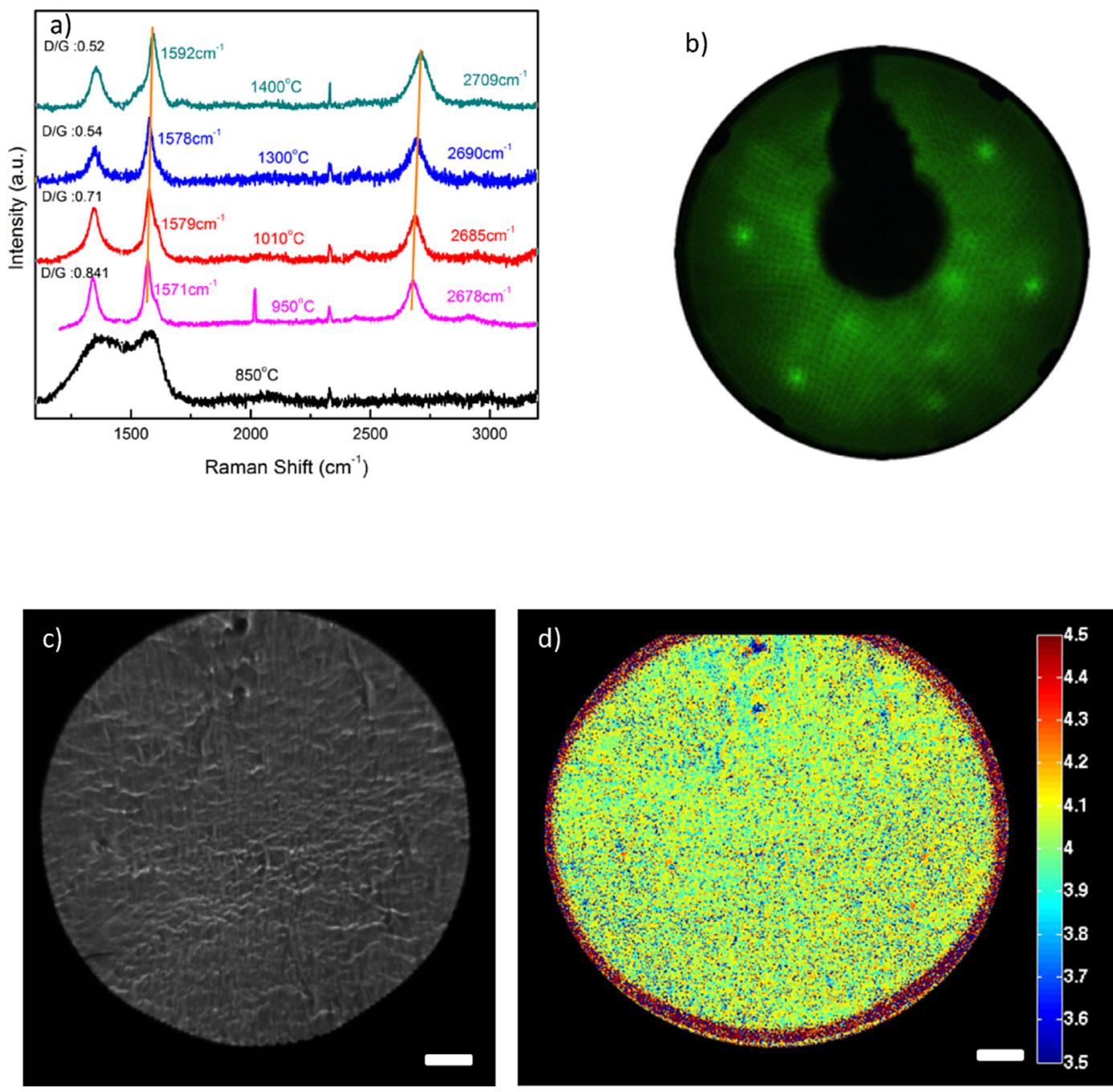

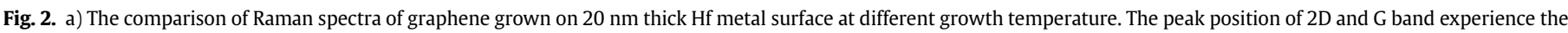

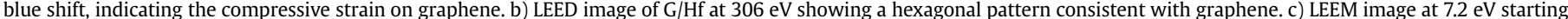

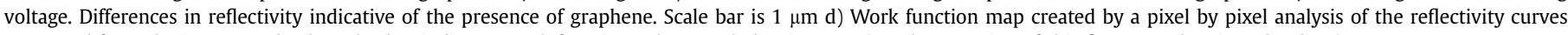
generated from the image stack. The color bar indicates work function values. Scale bar is $1 \mu \mathrm{m}$. (A colour version of this figure can be viewed online.)

microscopy (MEM-LEEM) transition was used to determine the spatially resolved work function across the surface. By acquiring a series of images as a function of increasing starting voltage a reflectivity curve can be generated for each pixel location in the image stack. Examining the voltage onset for each reflectivity curve a work function can be determined.[26] Fig. 2d shows the results from this analysis. The image is highly uniform across the surface with work functions values of $4.0 \pm 0.02 \mathrm{eV}$. These values are higher than what has been reported for HfC, [3.87 eV] [27] or Hf metal [3.95 eV] [28] and slightly lower than values reported for graphene on SiC.[29] The structural and electronic characteristics of the surface are further evidence for graphene formation as a result of the CMBE process.

Fig. 3 exhibits the change in chemistry during the $\mathrm{O}_{2}$ intercalation process. The graphene sample was grown by $\mathrm{C}_{60}$ $\left(3 \times 10^{-7}\right.$ Torr) deposition on $20 \mathrm{~nm}$ Hf layer. The growth temperature and time were $1400{ }^{\circ} \mathrm{C}$ and 90 min, respectively. The oxygen intercalation was performed under $1 \times 10^{-4}$ Torr oxygen pressure at $725^{\circ} \mathrm{C}$ as a function of intercalation time. HfC is clearly evident in the as-grown spectra shown in the high resolution $\mathrm{C} 1 \mathrm{~s}$ (Fig. 3a) and Hf $4 f$ (Fig. 3b) spectrum. After 60 min the peak associated with $\mathrm{HfO}_{\mathrm{x}}$ begins to emerge as shown in Fig. 3b. The peaks located at $14.1 \mathrm{eV}$ and $15.8 \mathrm{eV}$ correspond to the doublet associated with HfC. The binding energy at $16.9 \mathrm{eV}$ and $18.8 \mathrm{eV}$ is the same peak location as $\mathrm{Hf} 4 f$ doublet from $\mathrm{HfO}_{2}$ [15]. In the $01 s$ core level spectrum, Fig. 3c, we clearly observe the oxygen peak at $530.3 \mathrm{eV}$ attributed to $\mathrm{HfO}_{2}$ [30] after $60 \mathrm{~min}$ intercalation. At $180 \mathrm{~min}$, significant reduction of $\mathrm{HfC}$ atomic concentration and enhanced $\mathrm{HfO}_{2}$ concentration is observed. The atomic concentration ratio of graphene/HfC increased from 1.94 in as-grown sample to 11.8. The 01s spectra also exhibit the enhanced oxygen peak for $\mathrm{HfO}_{2}$. After $300 \mathrm{~min}$, we observe the complete conversion of $\mathrm{HfC}$ into $\mathrm{HfO}_{2}$ and only the peaks associated with $\mathrm{HfO}_{2}$ and graphene are present.

Fig. 4a shows the Raman comparison before and after $\mathrm{O}_{2}$ intercalation. The graphene was grown at $1400{ }^{\circ} \mathrm{C}$ for 90 min with $1.7 \times 10^{-7}$ Torr $C_{60}$ flux. As-grown sample show low $\mathrm{D} / \mathrm{G}$ ratio $(\sim 0.07 \pm 0.03)$, indicating lower defect density. The 2D peak is located at $2710 \pm 2 \mathrm{~cm}^{-1}$ with $\sim 37 \pm 5 \mathrm{~cm}^{-1}$ FWHM. Fig. 4a shows the Raman comparison before and after $\mathrm{O}_{2}$ intercalation. The graphene was grown at $1400{ }^{\circ} \mathrm{C}$ for 90 min with $1.7 \times 10^{-7}$ Torr $C_{60}$ flux. As-grown sample show low $D / G$ ratio $(\sim 0.07 \pm 0.03)$, indicating lower defect density. The $2 \mathrm{D}$ peak is located at $2710 \pm 2 \mathrm{~cm}^{-1}$ with $\sim 37 \pm 5 \mathrm{~cm}^{-1}$ FWHM. The $\mathrm{O}_{2}$ Intercalation process, red curve in Fig. 4a, shows no change on the Raman signature of our graphene. 

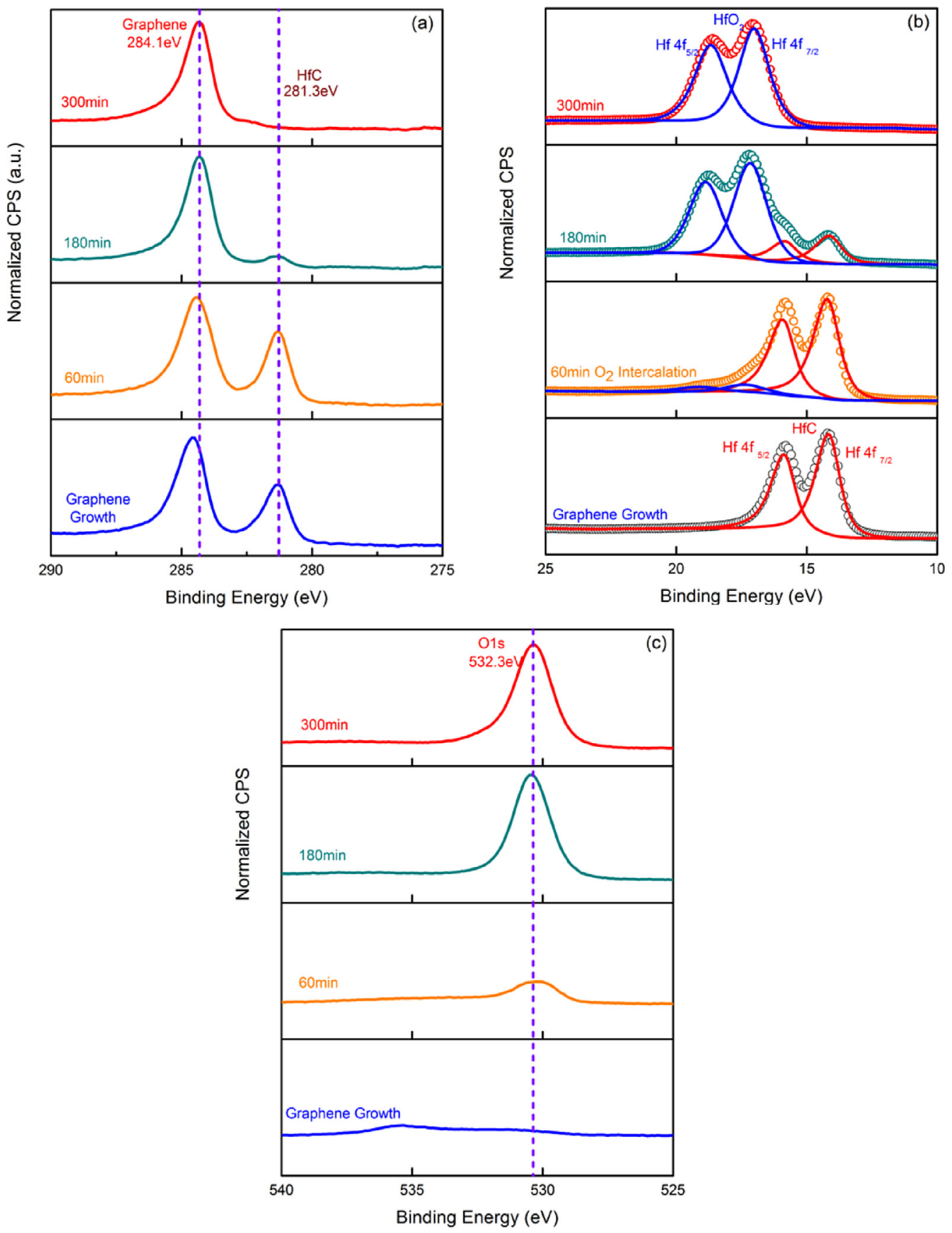

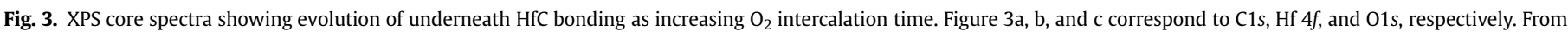

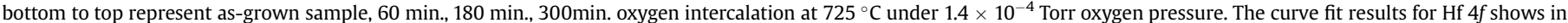

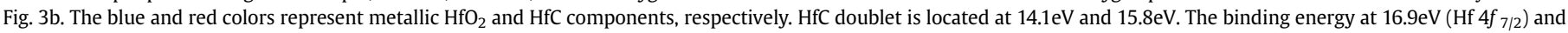
$18.8 \mathrm{eV}\left(\mathrm{Hf} 4 f_{5 / 2}\right.$ ) is corresponding to $\mathrm{HfO}_{2}$ doublet peaks. (A colour version of this figure can be viewed online.)

The $\mathrm{D} / \mathrm{G}$ ratio $(0.09 \pm 0.03), 2 \mathrm{D}$ peak position $\left(2711 \pm 1.8 \mathrm{~cm}^{-1}\right)$, and 2D FWHM $\left(\sim 24 \pm 9 \mathrm{~cm}^{-1}\right)$ remain unchanged after $\mathrm{O}_{2}$ intercalation. The fact that 2D peak position has no shift suggests that the high temperature intercalation does not induce any strain on graphene. The constant $D / G$ ratio also suggests that intercalation under $\mathrm{O}_{2}$ environment does not induce any defects on the graphene sample. Raman mapping was used to demonstrate the uniform formation of graphene $/ \mathrm{HfO}_{2}$ heterostructure. As shown in Fig. 4b and Fig. 2D peak position shows narrow variation within $\pm 1.8 \mathrm{~cm}^{-1}$ in the scanned area, which indicates the uniform formation of graphene on $\mathrm{HfO}_{2}$ layer. In addition, narrow variation of $\mathrm{G}$ peak position $\left(1584 \pm 3 \mathrm{~cm}^{-1}\right)$ was observed. In order for our approach to be a viable method for bottom gated graphene device applications, the leak current through $\mathrm{HfO}_{2}$ should be very low. Fig. 4c and d exhibit the leakage current measurement before and after intercalation, respectively. With $\pm 1 \mathrm{~V}$ gate voltage range, we obtain $\mathrm{pA}$ leakage current (Fig. 4d), which indicate that $\mathrm{HfO}_{2}$ layer obtained through intercalation has good dielectric characteristics. The room temperature transport measurement results in $260 \mathrm{~cm}^{2} / \mathrm{Vs}$ mobility, $7 \times 10^{13} \mathrm{~cm}^{-2}$ carrier concentration, p-type graphene. The obtained value is comparable to that of graphene directly grown on the $\mathrm{SiO}_{2}$ surface by CVD approach [31]. The graphene $/ \mathrm{SiO}_{2} / \mathrm{Si}$ grown by 

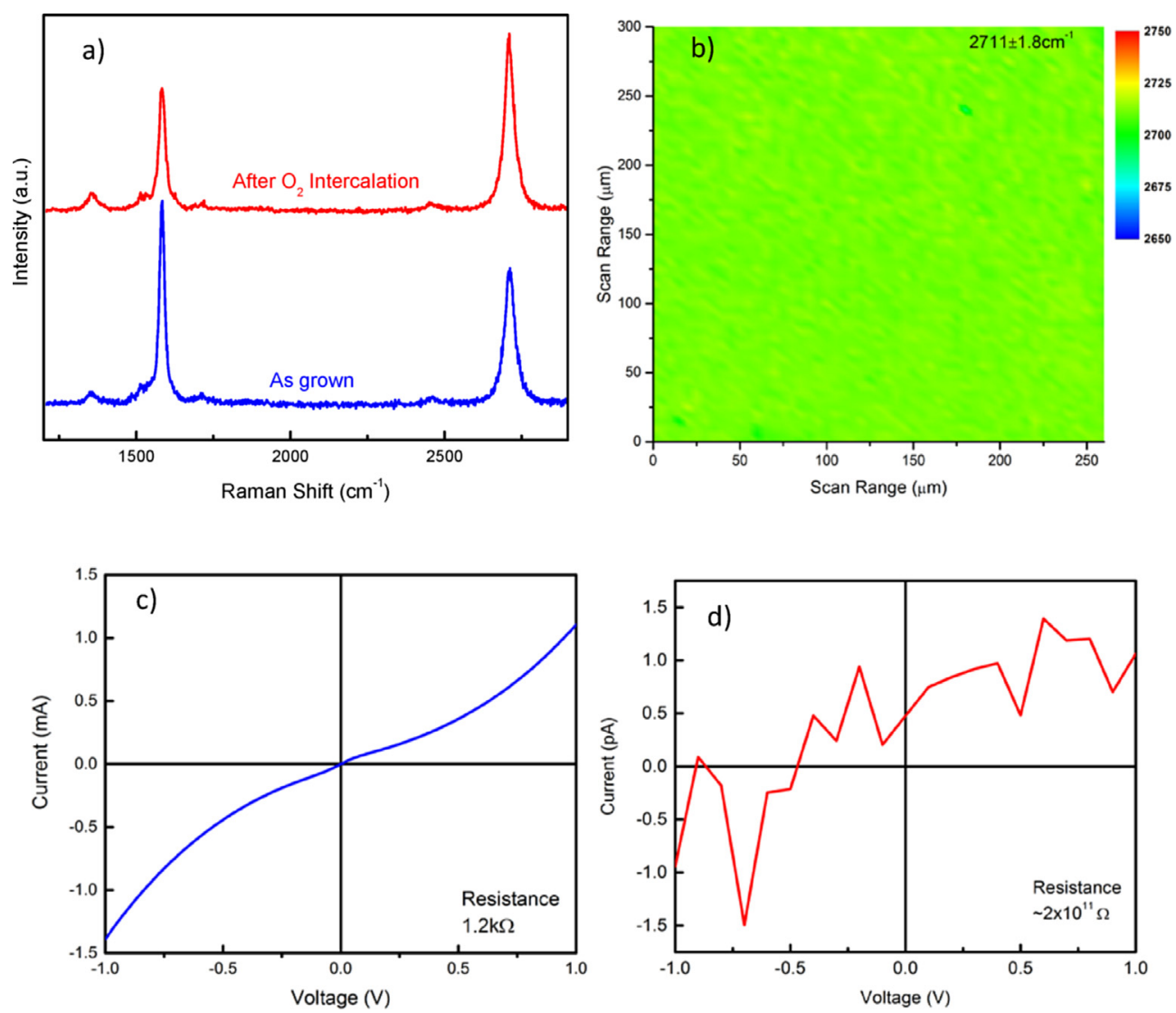

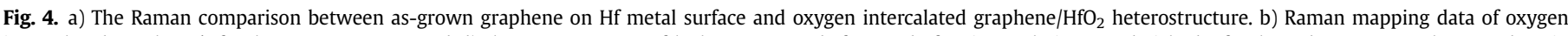

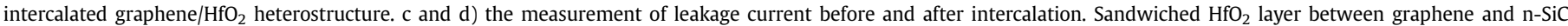
formed after intercalation. (A colour version of this figure can be viewed online.)

direct CVD showed that room temperature mobility ranges from $100 \mathrm{~cm}^{2} \mathrm{~V}^{-1} \mathrm{~s}^{-1}$ to $220 \mathrm{~cm}^{2} \mathrm{~V}^{-1} \mathrm{~s}^{-1}$.

\section{Conclusions}

We demonstrated that the large area graphene/dielectric layer heterostructure could be achieved by the solid carbon MBE approach, followed by oxygen intercalation. The direct growth of graphene on $\mathrm{HfO}_{2}$ layer resulted in graphene/HfC formation due to carbon reduction. To resolve metallic HfC formation, we adapted a high temperature oxygen intercalation process. After intercalation process, Raman measurement showed that the top graphene layer was not affected by $\mathrm{O}_{2}$ intercalation and the uniform graphene growth was confirmed. The obtained $\mathrm{Gr} / \mathrm{HfO}_{2} / \mathrm{n}-\mathrm{SiC}$ heterostructure showed the pico-ampere leakage current through underneath $\mathrm{HfO}_{2}$ layer. The $p$-type graphene with $260 \mathrm{~cm}^{2} / \mathrm{Vs}$ mobility on $\mathrm{HfO}_{2}$ was obtained by CMBE method incorporated with intercalation approach.

\section{Acknowledgments}

This work was supported by the Air Force Office of Scientific Research. We thank M. G. Landis for technical assistance.

\section{References}

[1] S.K. Banerjee, L.F. Register, E. Tutuc, D. Reddy, A.H. MacDonald, Bilayer PseudoSpin field-effect transistor (BiSFET): a proposed new logic device, IEEE Electron Device Lett. 30 (2) (2009) 158-160.

[2] L. Britnell, R.V. Gorbachev, R. Jalil, B.D. Belle, F. Schedin, A. Mishchenko,
T. Georgiou, et al., Field-effect tunneling transistor based on vertical graphene heterostructures, Science 335 (6071) (2012) 947-950.

[3] B. Samantha, L. Demetrio, F. Gianluca, L. Giuseppe, Vertical transport in graphene-hexagonal boron nitride heterostructure devices, Sci. Rep. 5 (2015), 14519: $1-10$.

[4] Y. Zhang, T.-T. Tang, C. Girit, Z. Hao, M.C. Martin, A. Zettl, et al., Direct observation of a widely tunable bandgap in bilayer graphene, Nature 459 (2009) 820-823.

[5] W. Yang, G. Chen, Z. Shi, C. Liu, L. Zhang, G. Xie, M. Cheng, D. Wang, R. Yang, D. Shi, K. Watanabe, T. Taniguchi, Y. Yao, Y. Zang, G. Zhang, Epitaxial growth of single-domain graphene on hexagonal boron nitride, Nat. Mater. 12 (9) (2013) $792-797$.

[6] A. Ismach, C. Druzgalski, S. Penwell, A. Schwartzberg, M. Zheng, A. Javey, J. Bokor, Y. Zhang, Direct Chemical vapor deposition of graphene on dielectric surfaces, Nano Lett. 10 (5) (2010) 1542-1548.

[7] X. Chen, B. Wu, Yunqi Liu, Direct preparation of high quality graphene on dielectric substrates, Chem. Soc. Rev. 45 (2016) 2057-2074.

[8] K. Aniruddha, F. Tian, J. Debdeep, Effect of high-к gate dielectrics on charge transport in graphene-based field effect transistors, Phys. Rev. B 82 (11) (2010) 115452.

[9] W.L. Scopel, A. Fazzio, R.H. Miwa, T.M. Schmidt, Graphene on amorphous $\mathrm{HfO}_{2}$ surface: an ab initio investigation, Phys. Rev. B 87 (16) (2013) $165307-165313$

[10] K. Zou, X. Hong, D. Keefer, J. Zhu, Deposition of high-quality $\mathrm{HfO}_{2}$ on graphene and the effect of remote oxide phonon scattering, Phys. Rev. Lett. 105 (12) (2010) 126601.

[11] S. Fratini, F. Guinea, Substrate-limited electron dynamics in graphene, Phys. Rev. B 77 (19) (2008) 195415-195420.

[12] K. Zou, X. Hong, D. Keefer, J. Zhu, Deposition of high-quality $\mathrm{HfO}_{2}$ on graphene and the effect of remote oxide phonon scattering, Phys. Rev. Lett. 105 (12) (2010) 126601.

[13] J.H. Park, W.C. Mitchel, L. Grazulis, H.E. Smith, K.G. Eyink, J.J. Boeckl, D.H. Tomich, S.D. Pacley, J.E. Hoelscher, Epitaxial graphene growth by carbon molecular beam epitaxy (CMBE), Adv. Mater. 22 (37) (2010) 4140-4145.

[14] T. Back, S.B. Fairchild, K. Averett, B. Maruyama, N. Pierce, M. Cahay, P. Terrence Murray, Pulsed-laser deposited transition-metal carbides for field-emission cathode coatings, ACS Appl. Mater. Interfaces 5 (18) (2013) 9241-9246.

[15] G. Carta, N. El Habra, G. Rossetto, G. Torzo, L. Crociani, M. Natali, et al., Growth 
of hafnium dioxide thin films by MOCVD using a new series of cyclopentadienyl hafnium compounds, Chem. Vap. Depos. 13 (11) (2007) 626-632.

[16] G.R. Gruzalski, D.M. Zehner, J.R. Noonan, H.L. Davis, R.A. DiDio, K. Müller, $(1 \times 1)$ rippled relaxation of $(100)$ transition-metal carbide surfaces, J. Vac. Sci. Technol. A 7 (3) (1986) 2054-2059.

[17] G.A. Swift, R. Koc, Formation studies of TiC from carbon coated $\mathrm{TiO}_{2}$, J. Mater Sci. 34 (13) (1999), 3083-93, 34.

[18] C. Riedl, C. Coletti, T. Iwasaki, A.A. Zakharov, U. Starke, Quasi-free-standing epitaxial graphene on SiC obtained by hydrogen intercalation, Phys. Rev. Lett. 103 (24) (2009) 246804-246807.

[19] Andrea C. Ferrari, Denis M. Basko, Raman spectroscopy as a versatile tool for studying the properties of graphene, Nat. Nanotechnol. 8 (4) (2013) 235-246.

[20] N. Ferralis, Probing mechanical properties of graphene with Raman spectroscopy, J. Mater Sci. 45 (19) (2010) 5135-5149.

[21] M. Huang, H. Yan, C. Chen, D. Song, T.F. Heinz, J. Hone, Phonon softening and crystallographic orientation of strained graphene studied by Raman spectroscopy, PNAS 106 (18) (2009) 7304-7308.

[22] G. Tsoukleri, J. Parthenios, K. Papagelis, R. Jalil, A.C. Ferrari, Ak Geim, et al. Subjecting a graphene monolayer to tension and compression, Small 5 (21) (2009) 2397-2402.

[23] A. Das, S. Pisana, B. Chakraborty, S. Piscanec, S.K. Saha, U.V. Waghmare, et al. Monitoring dopants by Raman scattering in an electrochemically top-gated graphene transistor, Nat. Nanotechnol. 3 (4) (2008) 210-215.
[24] S. Pisana, M. Lazzeri, C. Casiraghi, K.S. Novoselov, A.K. Geim, A.C. Ferrari, et al., Breakdown of the adiabatic Born-Oppenheimer approximation in graphene, Nat. Mater. 6 (3) (2007) 198-201.

[25] D. Yoon, Y.W. Son, H. Cheong, Negative thermal expansion coefficient of graphene measured by raman spectroscopy, Nano Lett. 11 (8) (2011) 3227-3231.

[26] Anderson ML, Nakakura CY, Kellogg GL reportImaging Doped Silicon Test Structures Using Low Energy Electron Microscopy SANDIA REPORT, Sandia US SAND 2009-7981.

[27] G.R. Gruzalski, S.-C. Lui, D.M. Zehner, Work-function changes accompanying changes in composition of (100) surfaces of HfCx and TaCx, Sur. Sci. 239 (1990) L517.

[28] Y.-C. Yeo, T.-J. King, H.U. Chenming, Metal-dielectric band alignment and its implications for metal gate complementary metal-oxide-semiconductor technology, J. Appl. Phys. 92 (2002) 7266.

[29] C. Mathieu, N. Barrett, J. Rault, Y.Y. Mi, B. Zhang, W.A. de Heer, et al., Microscopic correlation between chemical and electronic states in epitaxial graphene on SiC(0001), Phys. Rev. B 83 (23) (2011) 235436-235446.

[30] S.F. Choy1, V.S.W. Lim, R. Gopalakrishan, A. Trigg, L.K. Bera, S. Matthew, N. Balasubramanian, M.-S. Joo, B.-J. Cho, C.C. Yeo, AIP Conf. Proc. 683 (2003) 176.

[31] Z. Yan, Z. Peng, Z. Sun, J. Yao, Y. Zhu, Z. Liu, P. Ajayan, J. Tour, Growth of bilayer graphene on insulating substrates, ACS Nano 5 (10) (2011) 8187-8192. 